\title{
Médiévales
}

Langues, Textes, Histoire

60 | printemps 2011

La fitna

\section{Le poison et le sang dans la culture médiévale}

Poison and Blood in Medieval Culture

\section{Franck Collard}

\section{OpenEdition}

Journals

Édition électronique

URL : https://journals.openedition.org/medievales/6218

DOI : $10.4000 /$ medievales. 6218

ISSN : $1777-5892$

\section{Éditeur}

Presses universitaires de Vincennes

\section{Édition imprimée}

Date de publication : 30 juin 2011

Pagination : 129-155

ISBN : 978-2-84292-273-3

ISSN : 0751-2708

\section{Référence électronique}

Franck Collard, "Le poison et le sang dans la culture médiévale », Médiévales [En ligne], 60 | printemps 2011, mis en ligne le 19 janvier 2012, consulté le 22 avril 2022. URL : http://journals.openedition.org/ medievales/6218; DOI : https://doi.org/10.4000/medievales.6218 


\section{Franck COLLARD}

\section{LE POISON ET LE SANG DANS LA CULTURE MÉDIÉVALE}

Le sang est un objet d'histoire très observé depuis une vingtaine d'années chez les médiévistes ${ }^{1}$, invités par Huizinga en son temps à humer l' "odeur mêlée du sang et des roses» qu'aurait exhalée «l'automne du Moyen Âge». Cette hématoscopie historienne a déjà offert quelques beaux diagnostics. Outre les réflexions de J. Le Goff sur le tabou du sang et la dévalorisation des métiers ménageant un contact avec lui ${ }^{2}$ ou l'étude de M.-C. Pouchelle sur «Le sang et ses pouvoirs au Moyen $\hat{A}^{3} e^{3} »$, on peut rappeler quelques publications récentes, sans nulle prétention à l'exhaustivité. En 1997, le CRISIMA réunissait à Montpellier son quatrième congrès sur le thème du «sang au Moyen Âge ${ }^{4} »$. La Micrologus'Library a fait paraître en 2005 un volume collectif, le treizième de sa collection, intitulé Blood in History and Blood Histories ${ }^{5}$. Bettina Bildhauer a publié en 2006 un Medieval Blood privilégiant les sources germaniques ${ }^{6}$. L. Moulinier a fourni en 2004 un commode article de synthèse pour ce qui est de

1. Ce texte est la version remaniée d'une conférence faite à l'occasion du congrès de l'International Medieval Society, réuni en Sorbonne les 24-26 juin 2008 sur le thème du sang.

2. J. Le GoFf, «Métiers licites et métiers illicites dans l'Occident médiéval», dans ID., Pour un autre Moyen Âge, Paris, 1979, p. 91-107, voir p. 93.

3. M.-C. Pouchelle, «Le sang et ses pouvoirs au Moyen Âge», dans A. Farge éd., Affaires de sang. Mentalités, Paris, 1988, p. 17-41.

4. Le Sang au Moyen Âge, Actes du quatrième colloque international de Montpellier, université Paul-Valéry, 27-29 novembre 1997, éd. par le Centre de recherche interdisciplinaire sur la société et l'imaginaire au Moyen Âge, Montpellier, 1999.

5. M. Gadebusch Bondio éd., Blood in History and Blood Histories, Florence, 2005 (Micrologus'Library, 13).

6 B. Bildhauer, Medieval Blood, Cardiff, 2006. 
la dimension médicale de la question ${ }^{7}$. Enfin, pour citer un dernier exemple, la médiéviste de formation Vanessa Rousseau a produit, dans les mêmes moments, un ouvrage dense et inégal portant pour titre «Le goût du sang » et regardant en réalité davantage l'époque moderne ${ }^{8}$.

Si le thème suscite tant d'intérêt, si l'historien déjà ogre se fait volontiers vampire, c'est que le sang se place au carrefour de nombreux secteurs d'investigation historique, de l'histoire de la pensée médicale à l'histoire religieuse en passant par celle de la justice et par l'histoire sociale, sans oublier l'histoire politique qui a pris en compte le «sang royal ${ }^{9} »$. Il est aussi à la confluence de méthodes d'approche variées, linguistiques, anthropologiques, juridiques voire psychanalytiques. A priori, il semble en revanche bien éloigné du poison. Le venenum qui retient notre attention depuis des années ${ }^{10}$ paraît de prime abord utilisé précisément afin d'éviter - pour occulter - l'effusion de sang qui caractérise et matérialise le crime et il constitue l'arme non sanglante par excellence. Pourtant, quand le Religieux de Saint-Denis raconte l'ignoble meurtre par poison projeté par le roi de Navarre Charles le Mauvais contre les ducs de Berry et de Bourgogne en 1385, il écrit à propos du candidat au trône de France: sanguinem consanguineorum sitiret, il était assoiffé du sang de ses cousins ${ }^{11}$. Bien sûr, le récit très élaboré du chroniqueur cherche - et d'ailleurs trouve - l'effet de style. Mais il invite à aller voir de plus près les rapports que le poison peut entretenir avec le sang.

Il vaut donc la peine d'essayer de cerner les modes d'articulation rien moins qu'univoques du poison et du sang. Nous devons puiser dans un échantillon de sources nécessairement variées, narratives, juridiques et judiciaires, morales et religieuses, médicales et scientifiques, ces dernières constituant, à travers les traités des poisons en particulier, la documentation privilégiée parce qu'elle fait actuellement l'objet d'une enquête d'ensemble ${ }^{12}$. On commencera par voir les éléments de dissociation, voire d'opposition entre sang et poison. Ensuite seront abordés les éléments de rapprochement et de combinaison. Enfin, la question

7. L. Moulinier-Brogi, «Le sang entre savoirs et questionnements, science et imaginaire», Cahiers art et science, 8 (2004), p. 53-73 (= $\mathrm{n}^{\circ}$ spécial: 1453$)$.

8. V. Rousseau, Le Goût du sang, Paris, 2005.

9. A. Lewis, Le Sang royal, Paris, 1986 ( $1^{\mathrm{e}}$ éd. anglais, 1981). C. Beaune, «Les ducs, le roi et le Saint Sang», dans F. Autrand, C. Gauvard et J.-M. Moeglin éd., Saint-Denis et la royauté. Études offertes à Bernard Guenée, Paris, 1999, p. 711-732.

10. F. Collard, Le Crime de poison au Moyen Âge, Paris, 2003 ; ID., Poison et pouvoir. Histoire d'un crime politique de l'Antiquité à nos jours, Paris, 2007.

11. Chronique du Religieux de Saint-Denis, VI, 4 (éd. L.-F. Bellaguet, Paris, 6 vol., 18391852, réimpr. 1995, t. I p. 355).

12. Cette recherche sur les traités des poisons du Moyen Âge à la Renaissance doit faire l'objet d'un livre publié dans la collection «Micrologus». 
nodale du sang comme poison sera traitée avec quelque détail. Une facette supplémentaire du fascinant sang pourra ainsi, espérons-le, être sinon révélée par une cruentation intellectuelle, du moins éclairée.

\section{Veneficium abhorret a sanguine: deux univers séparés dans la sphère criminelle}

Le premier point de la réflexion se place essentiellement sur le plan de l'anthropologie criminelle, juridique et judiciaire. Deux aspects d'inégale importance sont à aborder: celui de la nature du crime de poison, crime sans effusion de sang; celui, plus secondaire, de son châtiment, le plus souvent non sanglant.

Sine effusione sanguinis sed horrendum scelus

Le sang que veut boire le roi de Navarre en faisant empoisonner ses ennemis par un de ses sbires n'est qu'une métaphore de la vie à enlever. Charles le Mauvais entend priver de sang, c'est-à-dire du fluide vital, les princes de (son) sang sans en répandre le sang, suivant une procédure meurtrière à l'exact opposé de celle de Jean sans Peur, qui, une vingtaine d'années plus tard, devait faire verser le sang du duc d'Orléans sur le pavé de Paris ${ }^{13}$. L'historien allemand Martin Kintzinger y a vu récemment un signe de mutation dans la résolution des conflits politiques, une sorte de retour à la voie de fait sanglante après un intermède de crimes dépourvus de sang, dont le crime de poison ${ }^{14}$. La subsistance d'affaires d'empoisonnements politiques en nombre non négligeable tout au long du Xve siècle rend l'hypothèse assez douteuse. Quoi qu'il en soit, à de rares exceptions théoriques près qui regardent des poisons inusités au Moyen Âge, le sang ne coule pas du corps quand le poison s'écoule dans l'organisme. Au temps de l'Empire de Rome, le pseudo Quintilien l'écrit déjà dans ses Declamationes : non spargit cruorem [venenatio] ${ }^{15}$. Anthropologues et ethnologues pourraient même voir dans l'empoisonnement une sorte d'implosion cachant à l'intérieur ce que le crime sanglant fait ressortir à l'extérieur, le sang signant et manifestant le crime alors que le poison l'escamote, l'occulte, l'intériorise.

13. Voir B. GuenÉe, Un meurtre, une société. L'assassinat du duc d'Orléans, 23 novembre 1407, Paris, 1992, notamment p. 29 et suiv.

14. M.Kintzinger, «Maleficium et veneficium. Gewalt und Gefahr für den Fürsten im französischen Spätmittelalter», dans M. KINTZINGER et J. RoGGE éd., Königliche Gewalt - Gewalt gegen Könige. Macht und Mord im spätmittelalterlichen Europa, Berlin, 2004, p. 71-99.

15. Ps. Quintilien, Declamationes XIX majores, éd. L. HaKansan, Stuttgart, 1982, $\mathrm{n}^{\circ} 17$, p. 346. 
L'économie du sang faite par l'empoisonneur répond-elle à une abhorratio sanguinis conditionnée par divers motifs ou à une stratégie de contournement qui serait dictée par la seule recherche d'une efficacité maximale assurée par l'occultation du crime et la vulnérabilité de l'agressé ? La première solution, évidemment la plus séduisante pour notre propos, doit chercher les raisons de ce rejet du sang du côté des toxicatores et, dans une moindre mesure, du côté des venenati. On pourrait penser que, quoique criminels de la pire sorte, certaines catégories d'empoisonneurs choisissent le venin pour ne pas avoir à transgresser des interdits, notamment canoniques. On songe évidemment aux clercs que l'abhorratio sanguinis de leur corps d'appartenance (Décret de Gratien, XXIII, 8) pourrait avoir plus particulièrement voués à l'usage du venin. Dans une moindre mesure, on pourrait aussi penser que l'appartenance d'une victime au clergé désignerait celle-ci à subir de préférence une forme de meurtre non sanglante. Hélas, le demi-millier de cas rassemblés par nos enquêtes passées ${ }^{16}$ invalide ces hypothèses. La condition ecclésiastique des victimes n'inspire aux meurtriers nulle crainte et nul refus de verser le sang. Les évêques agressés des $\mathrm{X}^{\mathrm{e}}$-XIII ${ }^{\mathrm{e}}$ siècles étudiés par M. Soria-Audebert ${ }^{17}$, les abbés et prieurs trucidés dans un bain de sang ${ }^{18}$ le prouvent. Et du côté des empoisonneurs, si les clercs ne manquent pas, il ne manque pas non plus des membres de l'Église pour ignorer, le temps d'un homicide, son horreur du sang. Les mauvais moines de Saint-Gildas-de-Ruys n'hésitent pas à se convertir au glaive devant l'insuccès des poisons destinés à Abélard ${ }^{19}$. Il faut donc en revenir à l'explication plus banale et, partant, plus décevante: élire le poison comme modus necandi ne veut pas dire refuser le sang par respect de lois plus fortes que le crime ou par respect des tabous. Cela signifie avant tout vouloir donner de l'efficacité par discrétion à son geste, donc enlever à la victime ses chances de se défendre.

Quelles que soient ses raisons, le modus agendi de l'empoisonneur place son crime en discordance complète avec la vision commune de l'homicide. Elle est étroitement liée au sang dans la culture antique et médiévale. Dans les codes

16. Voir n. 10.

17. M. Soria-Audebert, La Crosse brisée. Des évêques agressés dans une Église en conflit (royaume de France, fin $X^{e}$-début XIII siècle), Turnhout, 2005.

18. C'est le travail de doctorat que mène sous notre direction E. Lusset. Un article à paraître dans les actes du colloque Martyres (Nanterre, novembre 2009) sous le titre «Abbés et prieurs martyrs? Enquête sur les violences infligées aux supérieurs des communautés régulières au bas Moyen Âge» approfondit l'enquête esquissée par A. DimiER, «Violences, rixes et homicides chez les cisterciens », Revue des sciences religieuses, 46 (1972), p. 38-57.

19. Pierre Abélard, Historia calamitatum, éd. J. Monfrin, Paris, 1967, p. 107 : «Jam quidem non de veneno sed de gladio in jugulum meum tractantes...» 
barbares puis dans les coutumiers ${ }^{20}$, dans les pénitentiels aussi (l'article $35 \mathrm{du}$ pénitentiel colombanien pour les laïcs définit l'homicide comme le fait «d'avoir répandu le sang d'autrui») ${ }^{21}$, l'effusion de sang non seulement matérialise le crime mais donne l'échelle de sa gravité. Cet aspect se retrouve encore dans une ordonnance de 1381 et il détermine la lourdeur des peines ${ }^{22}$. La pratique judiciaire sanctionne les «battures à sang» plus lourdement que les simples bagarres, parce que l'écoulement de sang génère une souillure sociale à laver plus profondément ${ }^{23}$. Le recours au poison échappe à cette logique de même qu'à l'usage de la violence physique (origine de l'effusio sanguinis), même si la mort par empoisonnement passe pour occisio per vim comme le dit un acte de l'affaire concernant la comtesse Mahaut d'Artois après la mort suspecte de Louis $\mathrm{X}^{24}$. Mais la vis s'oppose simplement ici à la nature, violentée dans son cours normal.

Non violente et non sanglante, la toxicatio semble donc à part, étrangère aux horizons habituels de définition de l'homicide, elle échappe à la logique de l'échelle des crimes fondée sur un critère qu'elle évacue par sa procédure même et perturbe donc gravement le système de représentation des délits et des peines. Dans une conception formaliste et littérale des choses prédominante dans le haut Moyen Âge, cette caractéristique pourrait valoir l'impunité au venenator même son crime connu. La très négative perception du veneficium depuis l'Antiquité et tout au long des temps médiévaux s'explique aussi sans doute par le souci de déjouer ce piège. Il s'agit d'un horrendum scelus affirme le pape Jean XXII qui appuie la formule sur un rescrit d'Hadrien selon lequel «il est plus grave de tuer par le poison que par le glaive ${ }^{25}{ }$ », sans sang plutôt qu'avec, si l'on veut mettre les choses dans la perspective de cette enquête. Un passage des Miracles de Notre-Dame par personnages représentés à Paris au cours du XIV siècle oppose l'effusion de sang aux herbes et venins considérés comme de bien pires

20. Afin de ne pas énumérer les sources, on renverra à J.-M. CARBASSE, Introduction historique au droit pénal, Paris, 1990, p. 279 et C. GAUvarD, «De grace especial». Crime, État et société en France à la fin du Moyen Âge, 2 vol., Paris, 1991, chap. 18.

21. C. Vogel, Le Pécheur et la pénitence au Moyen Âge, Paris, 1969, rééd. 1982, p. 70.

22. X. Rousseau et M.-S. Dupont-Bouchat, «Le prix du sang. Sang et justice du XIV au XVIII ${ }^{\mathrm{e}}$ siècle», dans A. FARGE éd, Affaires de sang..., p. 43-71.

23. Voir C. Gauvard, «De grace especial», chap. 3 et 18.

24. M. De Godefroy Ménilglaise, «Mahaut, comtesse d'Artois », Mémoire de la société des antiquaires de France, 28 (1864), p. 181-230, Acte innocentant la princesse, octobre 1317, p. 208.

25. E. AlBE, Autour de Jean XXII: Hugues Géraud, évêque de Cahors, l'affaire des poisons et des envoûtements, Cahors-Toulouse, 1904, commission donnée pour l'instruction du procès d'Hugues Géraud, le 22 avril 1317, à Galhard de Riez,p. 163; Codex Justinianus, IX, 18 (éd. KrüGER-MommseN, Berlin, 1877, p. 379 [Corpus juris civilis, Berlin, 1872-1895, t. II]). 
moyens d'attenter à la vie d'autrui ${ }^{26}$. La parenté de l'empoisonnement avec la sorcellerie, visible dans l'emploi du même mot veneficium pour les désigner l'un et l'autre, provient notamment de cette commune procédure non sanglante mais néanmoins abominable ${ }^{27}$.

La troublante dématérialisation du crime commis par poison, c'est-àdire l'absence de plaies et de sang, paraît bien être une des clefs d'explication de la perception de la toxicatio comme horrendissimum scelus parce qu'en dissociant l'homicide du sang versé, elle vient brouiller les catégories criminelles et désorienter les esprits. Le défaut de sang fait sortir l'empoisonnement de la criminalité ordinaire, il faut donc affirmer bien fort la nécessité de sa répression et le ramener, comme fait le Religieux de Saint-Denis, aux crimes les plus sanglants.

\section{Qui a tué sans verser le sang périra de la même façon?}

L'examen des peines prévues pour les empoisonneurs et appliquées plus ou moins conformément aux normes fait apparaître en général un évitement du sang. Toute la question est de savoir si cet évitement se relie, par une analogie fréquemment présente dans le système pénal médiéval, aux modalités pratiques du crime châtié. Il est vrai que les textes juridiques prévoient la peine du feu pour les venefici et que cette peine se retrouve dans un certain nombre de cas pratiques ${ }^{28}$. Également non sanglant, et opéré indirectement par le feu, l'ébouillantement, en principe destiné aux faux monnayeurs, est aussi infligé, par exemple en Angleterre à partir de $1531^{29}$. Outre la volonté de terroriser d'éventuels candidats à l'emploi du venin par un supplice horrible qui devait d'ailleurs être remis en cause une trentaine d'années plus tard, il est possible de voir dans le choix de ce type de châtiment une raison analogique: aux décoctions qui transforment la matière en poison - les mêmes qui entrent dans les processus de fabrication de la fausse monnaie traditionnellement punie par l'ébouillantement - doit correspondre la lente «cuisson» du supplicié.

26. Miracles de Notre-Dame par personnages, éd. G. PARIS et U. RoBert, 8 vol., Paris, 18761893 , t. V, p. 178, miracle de Berthe, v. 650 et suiv. : à une dame épouvantée de voir son sang couler, le roi Pépin répond que ce n'est rien car son agresseur (la fille de sa servante) aurait pu tuer la dame «ou par herbe ou par venin» (v.654).

27. Sur cette parenté, voir F. Collard, «Veneficiis vel maleficiis. Réflexion sur les relations entre le crime de poison et la sorcellerie dans l'Occident médiéval », Le Moyen Âge, 109-1 (2003), p. 9-57.

28. Ces aspects normatifs et judiciaires sont traités dans notre Crime de poison, chap. 6, p. 216 et suiv.

29. K.J. KesselRing, «A Draft of the 1531 "Acte for Poysoning" », The English Historical Review, 468 (2001), p. 894-899. 
Mais, au vrai, l'absence de sang versé ne paraît pas un critère déterminant pour la fixation des modalités de la peine. Plusieurs arguments vont contre cette idée d'une correspondance entre le crime et son châtiment. Le droit canon refuse de considérer la peine capitale comme effusio sanguinis ${ }^{30}$. Par ailleurs, des modes non sanglants d'application de la peine capitale, telle la pendaison, viennent punir des crimes de sang. Comme l'écrivent X.Rousseau et M.-S.Dupont-Bouchat, «le sang répandu n'appelle qu'exceptionnellement le sang du coupable ${ }^{31} \gg$. Des empoisonneurs souffrent d'une mise à mort répandant leur sang, pour peu que la condition de leur victime en fasse des lèse-majesté : voir les sbires du roi de Navarre lors d'une précédente affaire mise au jour en $1378^{32}$. Symétriquement, la peine du feu prévue pour les impotionatores, encore prévue dans l'ordonnance de 1682, tire son origine de l'assimilation, remontant au droit romain, de l'empoisonnement aux pratiques magiques ${ }^{33}$. Certes, il est toujours possible de soutenir que cet apparentement reposant sur les évidentes similitudes qui existent entre des modes de nuisance sans contact et à saveur diabolique a entraîné, pour cette seule raison, l'absence de sang versé dans l'exécution capitale. Mais il faut bien plutôt y voir l'expression d'un commun rejet radical de deux crimes abominables dont il faut littéralement anéantir les adeptes, ce que le feu permet de réaliser.

Un rapport d'exclusion existe donc bel et bien entre poison criminel et sang. Il serait bien hasardeux d'en faire la traduction de la volonté délibérée des empoisonneurs. Cette exclusion de fait peut en revanche expliquer en partie la place à part de la toxicatio dans la perception des crimes au Moyen Âge occidental. Mais il est douteux que ce rapport ait conditionné le mode d'exécution des empoisonneurs. Surtout, ce rapport d'exclusion n'est en rien exclusif. Il souffre beaucoup d'exceptions. Poison et sang peuvent en effet parfaitement se combiner.

\section{Le sang au service du poison}

Au-delà du rapprochement essentiellement rhétorique fait par le Religieux de Saint-Denis, on peut trouver des terrains communs au poison et au sang: dans l'ordre criminel lui-même, avec une combinatoire constatée depuis les temps les plus reculés, mais qui pose problème; dans l'ordre médical ensuite, le sang étant

30. Yves de Chartres, Panormia, VIII, 53, Paris, 1647 et $P L$, t. CLXI, col. 1315 : «Homicidas et sacrilegos et venenarios punire non est effusio sanguinis sed legum ministerium.»

31. X. Rousseau et M.-S. Dupont-Bouchat : «Le prix du sang...»

32. Chronique des règnes de Jean II et de Charles V, éd. R. Delachenal, Paris, 4 vol., $1917-$ 1920 , t. II, p. 301.

33. F. Collard, Crime de poison...,p. p. 224 et 228. 
le vecteur par excellence du poison; dans l'ordre symbolique des représentations enfin, les deux matières ayant en commun la fluidité.

\section{Venenatio cum effusione sanguinis : le problème des armes empoisonnées}

La première combinaison entre sang et poison se rencontre dans une pratique qui remonte aux temps les plus anciens, qui affecte aussi la guerre et la chasse, et qui, à l'alternative agression sanglante/empoisonnement, substitue au contraire leur conjonction cumulative, invalidant l'hypothèse d'un choix du poison par refus du sang. La procédure qui consiste à enduire de poison glaives, poignards, flèches ou carreaux d'arbalètes pour entailler ou transpercer le corps d'un adversaire permet d'infecter le liquide vital qui circule dans les veines mais n'en exclut aucunement l'effusion. On peut s'interroger sur les raisons de cette alliance du coup sanglant et du venin perfide, l'interprétation la plus commune étant celle de la recherche d'une efficacité maximale. Mais il n'est pas interdit d'y voir aussi un rituel magique, accompli pour démultiplier la force destructrice de l'arme tranchante en faisant pénétrer dans l'organisme par son truchement des substances mystérieuses qui pallieront aussi éventuellement la maladresse de l'agresseur ${ }^{34}$.

Grégoire de Tours met en scène les meurtriers de Sigebert et Childebert, trempant leurs poignards dans un fort poison ${ }^{35}$. Il signale par ailleurs que les Francs, comme tant d'autres peuples guerriers, utilisaient du poison de flèche à base de végétaux ${ }^{36}$. Dans la guerre dite chevaleresque, mais en vérité dénaturée dès le XII siècle par l'usage des armes de trait qui ignorent le combat singulier entre pairs et sont abominées par l'Église (qui condamne au XII siècle l'usage de l'arbalète), le sang et le venin se combinent encore: Richard Cour de Lion passe pour être mort en 1199 d'un trait empoisonné, l'infection de sa plaie ayant sans doute été prise pour l'effet d'un quelconque poison ${ }^{37}$. La littérature ne manque pas d'exemple d'épées envenimées. Dans le cas de Tristan, ce sont l'épée du Morholt et la lance d'Estout qui passent pour avoir été trempées dans du poison ${ }^{38}$. Sans doute à cause des façons de faire des membres de la secte

34. Voir L. Lewin, Die Pfeilgifte, Berlin, 1894; E. Perrot et E. Vogt, Poisons de flèches et poisons d'épreuves, Paris, 1913.

35. Gregorius episcopus Turonensis, Historiarum libri decem (Zehn Bücher Geschichten Gregorius < Turonensis >), éd. B. Krusch et R. Buchner, Darmstadt, 1970, t. I, p. 270 et t. II, p. 196-198.

36. Ibid., t. I, p. 82.

37. Matthieu Paris, Chronica majora, éd. H.R. Luard, 7 vol., Londres, 1872-1883, trad. A. Huillard-BréHolles, 9 vol., Paris, 1841, t. II, p. 300 de la traduction.

38. Voir Les Fragments du Roman de Tristan, poème du XII siècle, éd. B.H. WIND, Genève, 1960, v. 1046 et suiv., p. 127-128: Tristan envenimé par l'épée du Morholt, et v. 2250 et sq.: Tristan 
des Assassins, cette combinaison de deux armes sanglante et non sanglante n'a pas disparu à la fin du Moyen Âge. Des traités des poisons comme ceux de Pietro d'Abano ou Sante Ardoini de Pesaro prennent en compte, avec la flèche empoisonnée, le gladius venenosus dont les coups causent une plaie à faire sucer d'urgence par un serviteur ayant l'esprit de sacrifice, ou à mettre au contact d'une pierre salvatrice ${ }^{39}$. En 1272, le futur Édouard $\mathrm{I}^{\mathrm{er}}$, blessé à Acre par un Assassin d'une dague qu'on croyait empoisonnée, ne doit son salut qu'à ce genre d'intervention ${ }^{40}$.

\section{Le sang vecteur du poison: les veines et le venin}

Les représentations des processus de l'empoisonnement donnent aussi la part belle au sang. Les traités de médecine ne sont pas les seuls à en faire le véhicule par excellence du poison dans le corps. L'idée a glissé dans les encyclopédies. Brunet Latin peut écrire au XIII ${ }^{\mathrm{e}}$ siècle dans Li livres dou tresor: «Et il est apelés venin por çou k'il entre dedens les vaines ${ }^{41}$ ». Il s'agit d'une conception qui s'appuie sur la similitude entre les deux mots relevée par Isidore de Séville (Étymologies, XII, 4) : les venena sont ainsi nommés non en raison de Vénus, comme le pensaient les Romains pour qui il s'agissait au départ de philtres d'amour, mais parce qu'ils s'insinuent et serpentent dans l'organisme par les venae, les veines, où coule un sang qui, sans que l'on n'en connaisse évidemment alors l'exacte circulation, n'en est pas moins considéré comme pouvant les transporter au cœur, siège de la vie. Isidore écrit même: non potest venenum nocere, nisi hominis tetigerit sanguinem, mais il ne parle que du venin de serpent ${ }^{42}$. C'est bien le calcul de ceux qui enduisent leur arme de n'importe quel poison.

Dans la littérature médico-toxicologique, la dérivation isidorienne aboutissant à venena depuis vena n'est pas invalidée ${ }^{43}$, quelle que soit la manière, violente ou non, d'intrusion du poison dans le corps. L'ingestion, voie la plus

touché par l'arme empoisonnée d'Estout l'Orgueilleux. Cf. C. CAHnÉ, Le Philtre et le venin dans Tristan et Iseut, Paris, 1975.

39. Pietro D'Abano, De venenis et eorum remediis, BnF, ms. 11230, f. 12 et chap. 80 sur les bézoards; SAnte Ardoini de Pesaro, Opus de venenis, livre V (Bâle, 1562, p. 327-328).

40. Chronographia regum Francorum, éd. H. Moranvillé, 3 vol., Paris, 1891-1897, t. I, p. 4 et Matthieu Paris, Chronica majora, continuation, trad. A. Huillard-Bréholles, t. IX, p. 172.

41. Brunetto Latini, Li Livres dou tresor, I, 136 (éd. F. J. Carmody, Berkeley, 1939-1948, réimpr. Genève, 1998, p. 132).

42. Sur Isidore et le concept de venenum, voir A. TouwAIDE, «De la matière à la nature. Les transformations d'un concept pathologique de l'Antiquité au début du Moyen Âge chez Isidore de Séville», Etym. XII, 4, dans A. Debru et G. Sabbah éd., Nommer la maladie, Saint-Étienne, 1998, p. $143-159$.

43. Exemple entre moult, Sante Ardoini de Pesaro, Opus de venenis..., I, 1. 
courante, entraîne un passage de la matière toxique dans le sang qui n'a donc pas besoin d'être directement en contact avec le venin pour être infecté, même si évidemment cette infection est plus assurée en cas de plaie sanguinolente enduite de poison, comme chez ce sultan dont Joinville rapporte l'histoire ${ }^{44}$. Une idée présente chez Avicenne et passée comme tant d'autres dans la pensée occidentale veut que l'ingestion d'un poison à jeun soit des plus dangereuses en raison de la large ouverture des veines que présente une personne en appétit: le venin arrive ainsi plus rapidement au cœur ${ }^{45}$. D'où la recommandation donnée par Jean Martin Ferrari de Parme d'après Pietro d'Abano: se couper la faim avant de se mettre à table en avalant des châtaignes ou des figues ${ }^{46}$. Même vulnérabilité veineuse pour les personnes de tempérament chaud chez qui le sang est le meilleur allié du venin ${ }^{47}$.

Une affaire curieuse connue par les archives du parlement de Paris illustre la large diffusion de cette conception selon laquelle le sang transporte le poison et donc s'en imprègne. En 1394, un patient du nom d'Arnaud Guilhom demande aux juges une expertise de son sang parce qu'il se croit empoisonné. Elle est faite par des médecins assermentés qui avouent que l'hématoscopie révèle difficilement la présence de poison: «Il n'est pas a plain traictié es livres de medecine comment on peust certainement congnoistre s'aucune personne est empoisonnée par l'inspection de son sang seulement ${ }^{48}$.» À une époque où l'observation doit se limiter à la couleur, à la fluidité, peut-être à l'odeur du sang et à sa saveur (le chirurgien Henri de Mondeville fournit toute une description interprétative des divers aspects du sang), la tâche est difficile, même si, dans le domaine voisin de la détection de la lèpre, elle parait très répandue ${ }^{49}$. En revanche, l'ouverture des cadavres, pratiquée en Italie dès les années 1300, permet de voir que le sang coagulé dans la région du cœur signe une toxicatio, ainsi que le disent des experts bolonais en $1335^{50}$. Sans doute s'agissait-il d'un poison froid. Vers 1290, dans ce que l'on peut tenir pour le premier traité des poisons écrit en Occident, le franciscain Juan Gil de Zamora donne l'exemple de l'opium qui épaissit tant la

44. Voir Joinville, Mémoires, éd. N. De Wailly, Paris, 1881, p. 51.

45. Avicenne, Liber canonis, Bâle, 1566, f. 911-912; reprise de l'idée par BERnARD DE GoRdOn, Lilium medicinae, Lyon, 1550, p. 53.

46. Jean Martin Ferrari de Parme, Liber de venenis evitandis eorumque remediis, BnF, lat. 6980, f. 3.

47. Bernard de Gordon, Lilium medicinae, p. 53.

48. Paris, Arch. nat., Parlement criminel, X 2a 12, f. 213v.

49. L. Moulinier, «Le sang... », p. 61-64.

50. J. Shatzmiller, «The Jurisprudence of the Dead Body. Medical Practition at the Service of Civic and Legal Authorities», Micrologus, 7 (1999) (= Il cadavere), p. 223-230, p. 229. 
masse sanguine qu'il en interdit bientôt l'écoulement ${ }^{51}$. La voie veineuse et le vecteur sanguin concourent puissamment à l'empoisonnement.

\section{La fluidité en partage}

L'étymologie sérieuse suggère un autre rapprochement entre le sang et le poison, rapprochement d'ailleurs à l'arrière-plan de l'idée de la diffusion du venin par le sang. C'est le mot virus qui désigne parfois le poison, dans le latin recherché d'un auteur comme l'évêque de Lisieux Thomas Basin par exemple ${ }^{52}$. Or ce mot est lié à une racine indo-européenne qui renferme l'idée d'écoulement ${ }^{53}$. Il est vrai que la consistance prédominante du poison ou plutôt de son vecteur (car le poison en lui-même consiste plus souvent en de la poudre qu'en une substance liquide), est ce qui lui a donné son nom français de «poison» (de potio, ce qui se boit). Cette consistance liquide ressemble à celle du sang. L'un et l'autre s'écoulent, l'un pour irriguer le corps, l'autre pour l'investir et le détruire en suivant les voies sanguines, après avoir coulé des végétaux vénéneux (suc) ou des animaux venimeux (venin des glandes de certaines bêtes).

Cette analogie se retrouve dans le parallélisme des thérapeutiques : à la saignée prescrite à ceux dont le sang présente un déséquilibre humoral répond l' «excorporation» du poison par écoulement, obtenu par divers moyens : classiques comme le vomissement ou les clystères, plus étonnant comme la pendaison par les pieds qui assure, croit-on, la sortie du venin par quelque orifice comme l'œil, ce qui aurait laissé borgne en 1295 le bien nommé duc d'Autriche Albertus monoculus ; écoulement par une canule comme celle qu'aurait portée Charles $\mathrm{V}$ empoisonné par le roi de Navarre ou par ses propres frères ${ }^{54}$. Il est à souligner que la saignée, si présente dans l'arsenal thérapeutique du temps, apparaît parfois comme moyen d'évacuation du poison même si Gentile da Foligno s'interroge sur sa pertinence ${ }^{55}$. Certes, lorsque l'organisme est empoisonné, c'est-

51. Juan Gil de Zamora, Contra venena et animalia venenosa, éd. M. CAStro, «El tratado contra venena de Fr. Juan Gil de Zamora», Archivo ibero-americano, 36 (1976), p. 23-117, p. 75. Une nouvelle édition vient d'être faite de l'œuvre par C. FERRERo-HernandEz, Liber contra venena et animalia venenosa, Barcelone, 2009.

52. Thomas Basin, Historia Ludovici undecimi, IV, 2: «letale virus» (éd. et trad. C. Samaran, 2 vol., Paris, 1963-1972, t. II, p. 130), Cf. Giovanni BalBi, Catholicon, Lyon, 1503, s v: « virus pro veneno accipitur.»

53. C. Воuлот, Le Venin, Paris, 2001, p. 13. Virus a d'abord le sens de suc, jus, humeur.

54. Sur les thérapeutiques, dont la pendaison par les pieds, voir F. Collard, Crime de poison..., chap. 2 p. 92 et suiv.

55. Vatican, Bib. Apost. Vat., lat. 2418, f. 209v-211 (recueil médical comportant des consilia de Gentile, dont un sur le poison, signalé par L. THORndiKe, An History of Magic and Experimental Science, 8 vol., Londres, 1923-1958, vol. III, p. 238. Signalons que dans un consilium concernant les soins à apporter à un individu mordu par un serpent aux environs de Pérouse vers 1345, Gentile 
à-dire assimilé par le poison, toute la masse sanguine est alors atteinte et rien ne servirait d'en évacuer une petite partie. Notons que c'est là une différence avec le traitement de la peste, mal volontiers assimilé à en poison, mais évacuable, croit-on, par saignée ${ }^{56}$. Mais si le venenum peut être circonscrit, alors la saignée permet d'évacuer la part du sang infecté ${ }^{57}$.

Le sang et le poison ne sont donc pas si inconciliables dans les savoirs du Moyen Âge occidental car l'empoisonnement du sang par divers processus, sans être théorisé, est bien envisagé. Il reste maintenant à prendre en compte l'empoisonnement par le sang d'autrui, le sang comme poison.

\section{Le sang-poison}

Le dernier degré de rapprochement du sang et du poison est celui de la fusion, si l'on peut dire: non la fusion par mélange, mentionnée au-dessus, mais la fusion par confusion qui fait du sang, dans certaines conditions, un poison «animal». Ici sont à mobiliser essentiellement les sources «toxicologiques » ou «Giftschriften» qui font souvent, comme le De venenis de Pietro d'Abano, les Problemata de venenis de Christoforus de Honestis, ou le gros volume composé vers 1455 par Jean Martin Ferrari ${ }^{58}$, une place spécifique à la question du sang-

da Foligno ignore toute saignée, préférant l'usage des ventouses. Texte édité et commenté par L. Thorndike, «A Case of Snake-Bite from the Consilia of Gentile da Foligno », Medical history, 5 (1961), p. 90-95.

56. L. MoulinieR, «La peste », p. 59. Sur les relations faites entre peste et poison, qui valent la composition de traités conjoints sur les deux sujets, voir notamment J. ArRIZABalaga, «Facing the Black Death: Perceptions and Reactions of University Medical Practitioners », dans L. GARCíABallester, R. French, J. Arrizabalaga, A. Cunningham éd., Practical Medicine from Salerno to the Black Death, Cambridge, 1994, p. 237-288; N. WeILL-PAROT, «La rationalité médicale à l'épreuve de la peste: médecine, astrologie et magie (1348-1500), Médiévales, 46 (2004), p. 73-88; M.P. CHASE, «Fever, Poisons and Apostemes. Autority and Experience in Montpellier Plague Treatises», dans P.O. Long éd., Sciences and Technology in Medieval Society, New-York, 1985, p. 153-169.

57. Voir Gilbert l'Anglais, Compendium medicine, Lyon, 1510, f. 355 : «contra morsum serpentis et aliorum venenosorum animalium aperiatur vulnus cum flebothomo et extrahatur sanguis » JEAN DE TOLÈDE, Liber de conservanda sanitate, éd. L. ElAUT, «The Walcourt Manuscript: A Hygienic Vade-Mecum for Monks », Osiris, 13 (1958), p. 187-209, p. 202, indique ce traitement dans la section sur les poisons ingérés tout en écrivant qu'il convient de mettre le doigt sur la blessure. Il réitère le conseil en cas de morsure par un chien enragé (204); BERNARD DE GORDON, Lilium medicine, Lyon, 1550 , p. 51, puis 61 : dans ce dernier passage, le médecin estime même qu'une saignée doit attendre trois jours, le temps que le poison soit répandu dans tout le corps. Il n'est toutefois question que du poison de la rage.

58. Pietro d' Abano, De venenis, chap. 71 ; Christoforus de Honestis, Problemata de venenis: Paris, BnF, lat.6910, f. 87r-113, traité 2, ultimes chapitres; Jean Martin Ferrari de Parme, Liber de venenis evitandis, IV, 14, 16, 17, 18. Voir textes en annexe. 
poison: sang des bêtes (taureau, lézards) et sang des humains (homme roux, femme en menstruation, lépreux).

\section{La toxicité du sang animal}

Les bestiaires et les traités des poisons de même que certains récits de voyages et descriptions du monde présentent des animaux dont le sang est réputé venimeux, soit parce que l'ensemble de la créature est venimeuse (le sang n'est alors qu'une composante toxique au même titre que le fiel, la salive, etc..$^{59}$ ), soit parce que, et Jean Martin de Ferrare en fait le quatorzième chapitre de son traité sur la division des poisons (de animalibus quorum sanguis est venenosus) ${ }^{60}$, le sang est une des ou la seule composante(s) toxique(s), à l'état naturel, comme le sang des canards pontiques nourris aux herbes vénéneuses de la Colchide $^{61}$.

Le sang de taureau est de la dernière catégorie. Un certain nombre d'auteurs y consacrent un chapitre dans leur description des poisons animaux, chapitre souvent plus descriptif qu'explicatif: ainsi procède vers 1375 Francesco Casini de Sienne pour qui c'est l'un des cent quarante-deux poisons de l'univers ${ }^{62}$. Son contemporain Guillaume de Marra décrit, pour le pape Urbain V, les maux qu'il provoque: difficultés respiratoires, nausées, douleurs stomacales dues à sa viscosité et sa lourdeur ${ }^{63}$. Le sang de taureau frâ̂chement extrait est pire que tout. Il se congèle dans l'estomac estime Christoforus de Honestis ${ }^{64}$. C'est pour lui l'un des rares poisons auquel le vomissement est un remède pire que le mal car il risquerait d'étouffer le patient, propos repris presque à l'identique par Jean Martin Ferrari de Parme ${ }^{65}$.

D'autres bêtes possèdent un sang toxique parce qu'elles sont substantiellement venimeuses. Si leur sang n'est pas la résidence exclusive de leur toxicité, il peut cependant présenter aussi un danger. Les serpents, les crapauds

59. Pietro d'Abano, De venenis, chap. 2.

60. Jean Martin Ferrari de Parme, Liber de venenis evitandis, Oxford, Bodl. Can. Misc. 127, $2^{\mathrm{e}}$ partie, $1^{\mathrm{e}}$ traité, chap. 14 .

61. T. Reinach, Mithridate, roi de Pont, Paris, 1890, p. 283-285.

62. Franciscus Casini, Tractatus de venenis, Paris, BnF, lat.6979, f. 27 : «Capitulum quartum partis prime de numeratione omnium venenorum. Sunt ergo venena in universo centum et quadraginta duo.»

63. Guillaume de Marra, Sertum papale de venenis (1362), Metz, BM 282, f. 41-42. Voir texte en annexe.

64. Christoforus de Honestis, Problemata de venenis (vers 1390), Londres, British Library, Harley 3659, f. 51v-52. Voir texte en annexe.

65. Jean Martin Ferrari de Parme, De vitandis venenis (1455), Oxford, Bodl., Can. Misc. 127, chap. 18: «Vomitus non est provocandus in talibus timore suffocationis; vomitus est praecavendus in tallibus timore prefocacionis.» Voir texte en annexe. 
(à la bave encore plus dangereuse selon Antonio Guaineri ${ }^{66}$ ) ou les lézards relèvent de cette catégorie. Guillaume de Marra décrit les atteintes causées par l'absorption de sang de crapaud: maux cardiaques et mort rapide résultent de ce poison froid ${ }^{67}$ retrouvé aussi chez le lézard comme le signale Jean Martin Ferrari de Parme dans un chapitre intitulé De bibente sanguinem botracis (IV, 14). Même si ce n'est pas notre sujet, observons au passage que ces exemples d'ingestion de sang animal ne sont à peu près jamais replacés par les auteurs dans un contexte social. On y reviendra.

\section{La toxicité du sang humain}

La question de la toxicité du sang humain se pose à plusieurs niveaux différents. On imagine qu'il existe du sang naturellement toxique, du sang corrompu par l'air (sang figé ou caillé, pris en compte en général avec le lait ${ }^{68}$ ) et du sang rendu empoisonné par la maladie, assimilée fréquemment à un poison s'emparant de l'organisme sans opération autre que naturelle, venenum in corpus generatum comme dit le Pietro d'Abano qui reprend la tradition galénique ${ }^{69}$. Dans les actes du second procès de Pierre Gerbais, trésorier de Savoie accusé d'avoir empoisonné le sire de Grammont (1375), les médecins consultés pour expertise indiquent que le sang (une des quatre humeurs) peut devenir poison ${ }^{70}$. Mais la classification des sangs-poisons humains par les spécialistes se limite souvent à quelques catégories consacrées.

La première espèce concerne le sang menstruel. Les menstrues des femmes sont vues comme l'évacuation de superfluités nocives (mélancoliques) selon une vieille tradition remontant à Aristote, Galien et Pline et remise en vogue par Barthélemy l'Anglais au XIII ${ }^{\mathrm{e}}$ siècle ${ }^{71}$. «Les fleurs est ung venin plus

66. Antonio Guaineri, De venenis (1422), dans ID., Opus praeclarum, Paris, 1525, f. 244 ou ms. Paris, BnF, lat.6981, f. 196. Voir texte en annexe.

67. Voir n.61.

68. Nicolas Falcucci de Florence, De dispositionibus venenorum: Paris, BnF lat. 6985, f. $75 v^{\circ}-117 v^{\circ}$ et édition: Venise, 1507. Le chap. 28 s'intitule dans l'édition de 1507 De nocumentis provenientibus ex sanguine hominis et sanguinis et lactis congelatorum. Cette association se trouve dans la littérature médicale arabe: voir RHAzès, Continens, livre 35, 4e traité, f. 498 de l'éd. de Venise de 1542.

69. Pietro d’Abano, Conciliator, Venise, 1565, quaestio 91, p. 138, col. 2. Sur ce thème, voir P. LEvron, «La mélancolie et ses poisons: du venin objectif au poison atrabilaire», Cahiers de recherches médiévales, 17 (2009) (= F. Collard éd., Le Poison et ses usages dans l'Occident médiéval), p. 173-188.

70. S. Moyard, Crime de poison et procès politique à la Cour de Savoie. L'Affaire Pierre Gerbais (1379-1382, Lausanne, 2008, p. 207 (Cahiers lausannois d'histoire médiévale, 44).

71. Voir D. Jacquart et C. Thomasset, Sexualité et savoir médical au Moyen Âge, Paris, 1985, p. $98-109$. 
malvaiz et dangereuz que venin de serpent» affirme une variante des Secrés as philosophes ${ }^{72}$. Les auteurs de traités des poisons consacrent généralement quelques lignes à la question. Ce sang est-il mortel? Jean Martin Ferrari de Parme ne parle que des accidentia in bibente sanguinem menstruum apparentia ${ }^{73}$ mais Arnaud de Villeneuve (ou un disciple) écrit au début du XIV siècle que le sang menstruel, froid et $\mathrm{sec}$, tue ou donne la lèpre ulcéreuse ${ }^{74}$. Il reprend peutêtre Geber qui, dans son Liber de floribus naturarum estimait que boire du sang menstruel donne la lèpre et se baigner dedans tue ${ }^{75}$. En réalité, outre le fait que certains, lecteurs de Pline, ne perçoivent, pas le sang menstruel comme uniformément mauvais ${ }^{76}$, ses effets sont d'un autre ordre. Il provoque plutôt des lésions mentales à cause des vapeurs qu'il génère et qui montent au cerveau : lunatisme (lié bien entendu au cycle lunaire des règles), ensorcellement, amnésie, maléfice (avec des variantes: patient maléfique ou maléficié), stupidité, etc. ${ }^{77}$. Le sang menstruel tari, une fois la femme ménopausée, les mauvaises humeurs doivent s'évacuer par d'autres orifices comme les yeux, ce qui donne le mauvais œil de la vetula ${ }^{78}$. De la nocivité matérialisée par le sang, on passe à la nuisance sans support matériel mais l'on demeure bien dans le registre du veneficium avec son sens «sorcier».

Signalons aussi la réputation vénéneuse du sang de l'homme roux en colère, la rousseur étant rapportée aux circonstances impures et sanguinolentes de la conception par certaines versions du Placide et Timeo ${ }^{79}$. Les traités des poisons des $X V^{\mathrm{e}}$ et $\mathrm{XV}^{\mathrm{e}}$ siècles consacrent volontiers un chapitre à ce sang empoisonné qui affecte l'entendement, détruit le sentiment de pudeur, voire rend fou à cause des vapeurs émanant d'un sang léger, chaud et sec, vapeurs qui gagnent le cerveau $^{80}$.

72. Placides et Timeo ou li secrés as philosophes, éd. C. ThомAsset, Genève-Paris, 1980, p. 264.

73. Voir texte en annexe.

74. Arnaud de Villeneuve, De venenis, Lyon, 1520, f. 219: «Menstruus sanguis necat vel infert lepram ulcerosam.»

75. Sante Ardoini de Pesaro, Liber de venenis (vers 1425), IV, 25 (Venise, 1492, f. 50). Voir texte en annexe et C. Burnett et D. Pingree, «Between the Ghâya and the Picatrix, II: The Flos naturarum ascribed to Jâbir», Journal of the Warburg and Courtauld Institute, 72 (2009), p. 41-80.

76. Pline L’AnCien, Histoire naturelle, éd.-trad. Littré, Paris, 2 vol., 1848-1850, VII, 13, t. I p. 289 et XXVIII, 23, t. II, p. 263.

77. Voir les textes en annexe.

78. Voir J.Agrimi et C. CRISCIANI, «Savoir médical et anthropologie religieuse. Les représentations de la vetula $\left(\mathrm{XIII}^{\mathrm{e}}\right.$-XVe siècle)», Annales. Économies, Sociétés, Civilisations, 1993, p. 1281-1309.

79. Placides et Timeo..., p. $264:$ :Se femme conchoipt en ce tandis [durant ses règles] l'enfant sera puant, rouz, tachié et malcheant.»

80. Voir les textes en annexe. Seul Antonio Guaineri s'abstient de composer une rubrique spéciale. Ce sang entre dans les recettes alchimiques aux ingrédients souvent empruntés au monde 
Le sang humain est aussi un poison en cas de maladie. Les mauvaises humeurs accumulées en raison d'une pathologie infectent la masse sanguine. Celui des lépreux, rendus malades par une altération de la mélancolie (déséquilibre humoral), est réputé toxique par Pietro d'Abano et bien d'autres qui en traitent souvent dans la même rubrique que le sang menstruel ${ }^{81}$ et lui attribuent des effets identiques $^{82}$, encore que Guillaume de Marra les distingue ${ }^{83}$. Le lien entre le sang menstruel et le sang du «mesel» est facile à faire puisque la lèpre est censée atteindre ceux qui ont été conçus en période de menstruation: leur mauvais sang est donc originel. Mondeville signale que la rareté de la lèpre chez les juifs provient précisément de leur respect scrupuleux de l'obligation d'abstinence sexuelle en temps de règles ${ }^{84}$.

\section{Des traités aux pratiques: un emploi rare?}

Le sang à lui seul peut donc en théorie être toxique. Mais le retrouvet-on employé dans la documentation judiciaire ou autre? Des traités des poisons rapportent certes des exempla d'empoisonnement par de la matière sanguine toxique, notamment au sujet du sang menstruel. Guillaume de Marra indique avoir connu une femme qui, ignorant la nocivité du produit et le croyant seulement destiné à rallumer les feux de l'amour, avait tué deux maris ${ }^{85}$. Mais, significativement, Sante Ardoine renvoie ces histoires à la tradition orale, n'ayant rien lu dans les ouvrages savants sur ces femmes de peu de vertu qui dissimulent quelques gouttes de sang menstruel dans les plats de leurs amants ${ }^{86}$.

En dehors de cette littérature spécialisée, les usages du sang-poison affleurent dans quelques sources. Comme il n'existe pas de transfusion (les premières apparaissent au XVII ${ }^{\mathrm{e}}$ siècle), c'est essentiellement par ingestion de sang empoisonné que peuvent survenir des empoisonnements, soit accidentels soit criminels. L'ingestion du sang de taureau peut être médicinale voire plus ou moins magique, en vue de refaire ses forces ou incorporer sa force ${ }^{87}$; jusqu'à

des poisons. Je remercie bien volontiers A. Vinciguerra d'avoir attiré mon attention sur cet aspect.

81. Voir textes en annexe. Antonio Guaineri commence ainsi son chapitre intitulé De sanguine menstruo: Qui sanguinem menstruum sumpserit aut leprosi... Même procédure chez Jean Martin Ferrari de Parme.

82. Voir le texte en annexe de Christoforus de Honestis, extrait 2.

83. Voir texte en annexe, extraits 3 et 4 .

84. Sur les interprétations médiévales de la lèpre, voir F. O. Touatı, Maladie et société au Moyen Âge. La lèpre, les lépreux et les léproseries dans la province ecclésiastique de Sens jusqu'au milieu du XIV siècle, Paris-Bruxelles, 1998. Ici, p. 725.

85. Voir texte en annexe.

86. Voir texte en annexe.

87. Sur l'ingestion de sang dans les régimes alimentaires, voir V. Rousseau, Le Goût du sang..., chap. 7. 
l'administration forcément criminelle du sang de crapaud - l'empoisonnement par sa bave relève en revanche de l'accident ${ }^{88}-$, il y a de multiples circonstances d'empoisonnement par le sang. Les pénitentiels du haut Moyen Âge indiquent que le sang menstruel entre dans des substances parfois composées au titre de philtre de désamour, de stérilité ou au contraire d'affection. Celui de Raban Maur parle de illa femina quae menstruum sanguinem suum miscuit cibo vel potui, et dedit viro suo ${ }^{89}$. Certaines affaires venues en justice ou connues par des chroniques montrent le sang comme ingrédient de mixtures censées empoisonner ceux qui les prennent. Lors de l'affaire de 1321, les lépreux censés avoir voulu empoisonner les puits du royaume de France avouent que les poudres jetées dans les eaux étaient faites notamment d'urine et de sang provenant de reptiles venimeux mais, notons-le, pas de leur propre sang pourtant réputé toxique ${ }^{90}$. Les empoisonneurs de 1390 usent de sang de crapaud ${ }^{91}$. Nulle part n'est dépeinte en revanche la collecte, à des fins criminelles, du sang de l'homme roux en colère.

Le sang peut ainsi être poison, classé parmi les venena animaux. La substance vitale par excellence qu'il est peut aussi être substance mortelle en elle-même. C'est une facette de son équivocité qui se lit aussi dans le sang versé par le Sauveur, symbole mixte de la mort subie et de la régénération donnée à la multitude.

Le poison s'articule donc de multiples façons avec le sang, de l'exclusion à la confusion. Comme force destructrice alors que le sang est force vitale, comme arme «sèche » évitant le flot de sang, le poison s'oppose au sang tout en pouvant être associé à lui par combinaison criminelle, coopération physiologique ou similitudes matérielles. Ce double rapport d'opposition et d'association permet, en même temps qu'il la rend paradoxale, voire monstrueuse, la pensée d'un sangpoison qui possède d'ailleurs, comme tout pharmakon, son opposé déjà relevé par Henri de Mondeville: le sang-remède, remède licite car fortifiant, régénérant,

88. Voir la septième nouvelle de Boccace, Decameron, éd. E. Pognon, Boccace, le «Décaméron": manuscrit enluminé du XV siècle, Fribourg-Genève, 1978 (ms. 5070 de l'Arsenal); Boccace, Décaméron, trad. sous la dir. de C. Bec, Paris, 1994, p. 386: histoire de la Florentine Simone, pauvre fileuse de laine, qui aime un pauvre commissionnaire, Pasquino; un jour qu'il mange dans un jardin, celui-ci se frotte les dents avec de la sauge et meurt sur le champ; on découvre un énorme crapaud au pied du buisson; son venin s'était communiqué à la plante par les racines.

89. Raban Maur, Pénitentiels, dans PL 110, pénitentiel de 841, adressé à l'évêque d'Auxerre, chap. 30 .

90. JACQues Fournier, évêque de Pamiers, 1318-1325, Registre d'inquisition, éd. J. Duvernoy, Toulouse, 3 vol., 1975, t. II, p. 135-144.

91. Registre criminel du Châtelet, éd. H. Duplès-Agier, Paris, 2 vol., 1861-1864, t. I, p. 311 322 et $409-480$. 
susceptible de donner à qui en prend la force de l'animal dont il provient ${ }^{92}$. Un traité anonyme copié vers 1448 et intitulé De venenis intoxicantibus et eorum remediis l'indique très clairement: Sanguis frescens est antidotum contra omne venenum $^{93}$. De même, le sang du Christ a été versé pour détruire le poison symbolique qu'est le péché ${ }^{94}$.

La société médiévale a surmonté le tabou vétérotestamentaire du sang et fait du sang du Christ veneficus (au sens positif de fabricant de teinture) une thériaque rédemptrice. Bernardin de Sienne, en un sermon de Carême, clame: Veneficus enim Christus est id est tinctor, qui vestes suas sanguine suo proprio tinxit ${ }^{95}$. Ce remède de régénération est toutefois interdit quand c'est du sang humain, et notamment du sang frais d'enfant. Ce «vampirisme» royal a été reproché à Louis XI ainsi transformé, comme le roi de Navarre avec qui nous avons commencé, en tyran assoiffé de sang, capable d'en boire pour prolonger sa vie, capable aussi de tendre les pires embûches toxiques ${ }^{96}$. L'affaire du sang contaminé, dont une des qualifications juridiques envisagées fut l'empoisonnement, a montré la longévité du fantasme faisant des autorités politiques de redoutables utilisatrices du sang des peuples.

92. M.-C. Pouchelle, «Le sang et ses pouvoirs...», p. 18; H. Bettin, «Das therapeutische Gebrauch von Blut im mittelalterlischen Abendland», dans M. GADEBusch Bondio éd., Blood in History..., p. 69-89.

93. De venenis intoxicantibus et eorum remediis, BAV, Pal. Lat. 1177, f. 201-203, f. 201v.

94. Voir F. ChaVe-MAhiR, «Venenum sub melle latet. L'image du poison dans le discours antihérétique au Moyen Âge», dans F. Collard, Le Poison et ses usages..., p. 161-172.

95. Bernardin de Sienne, Sermons de Carême, dans Id., Opera omnia, Paris, 1635, sermon 15 , p. 533 .

96. Sur les multiples affaires de poison auxquelles Louis XI fut mêlé, voir F. Collard, Crime de poison... et ID., Pouvoir et poison... Sur la rumeur de la consommation de sang d'enfant par le roi, voir Robert GaGuin, Compendium de origine et gestis Francorum, Paris, 1500/1501, f. 160v: «humano sanguine quem ex aliquot infantibus sumptum hausit salutem comparare vehementer sperabat.» 


\section{Annexe : le sang-poison dans quelques traités des poisons des $\mathrm{XIV}^{\mathrm{e}}$ et $\mathrm{XV}^{\mathrm{e}}$ siècles}

1 - Pietro d'Abano, De venenis et eorum remediis, vers 1310, Paris, Arsenal 873, f. 121-121v., ici dans la traduction de Philippe Ogier pour Boucicaut, Paris, BnF fr. 14820, f. 37v.-38, ch. 70-73, vers 1402

\section{a) Du sang de vieil buef}

En ce chappitre dit le maistre que cellui a qui seroit donné sang de vieux bœuf en buvrage si doit souffir comme morsure de beste envenimee ${ }^{97}$ et doit vomir vomissement congelé. Et dit le maistre que la cure si est vin aigre et chaut et après doit le pacient vomir et après on doit donner tyriacle au pacient et après on doit faire la personne baigner en yaue chaude.

\section{b) Du sang de crappaut}

En ce chappitre dit le maistre que cellui a qui seroit donné le sang du crappaut si doit avoir defaute d'alaine et cardiaca accidenta. Et dit que cellui qui aroit pris ou prise de son escume il seroit en peril de mort comme cellui qui aroit beu napellus. Et dit le maistre que la cure si est le buvrage fait de l'esmeraude z I et après doit le pacient entrer dedans une beste a iiii piez comme dit est dessus si comme seroit en un boef ou asne ou mulet ou cheval et souvent y entrer et cent jours avoir freche beste ${ }^{98}$ et apres doit le pacient prendre et boire du tyriacle ii z. Et dit que le bezoar si est une pierre qui se troeuve en la teste du crappaut qui s'appelle selon les lapidaires boras et en franchois crappaudine.

\section{c) Du sang de homme colerique}

En ce chappitre dit le maistre que cellui a qui seroit donné le sang de homme colerique roux qui seroit en son ire ou en sa fureur si doit souffrir fureur et ire en son courage et mue en l'entendement et est sans vergongne. Et dit le maistre que la cure si est boire de l'yaue de concourbe palestini ${ }^{99}$ et doit le pacient mascher les grains de concourbe et doit avaler le gut et boire du sirop nemissarum ${ }^{100}$. Et dit le maistre que le bezoar est cocistus ${ }^{101}$ unus de tyra ${ }^{102}$.

\section{d) Du sang menstrueux ou du mesel}

En ce chappitre dit le maistre que cellui a qui seroit donné le sang menstrueux ou de mesel en buvrage si devroit estre pistrigatus 103 et lunatique et maleficieux et oblieux.

97. Texte latin, d'après Paris, Ars 873, f. 121 : «pacietur mortificationem».

98. Manque.

99. cucumeris palestrini

100. nenufarum

101. trociscus

102. Manque mais présent dans l'éd. de 1473.

103. Pestigiosus 
Et dit le maistre que sa cure si est bonne marguerites broiees z l avecques yaue mellisse et se doit baigner en yaue tiede et doit congnoistre une pucelle charnellement selon la loy et doit converser et acoler souvent jeunes pucelles. Et dit que le bezoar est que le pacient doit mangier serpens aux quelz on doit oster le long d'une palme a la cueue et a la teste et copper et getter hors.

2 - Guillaume de Marra, Sertum papale de venenis, 1362, Metz, BM ms. 282, f. 41-42

\section{a) De sanguine buffonis}

Sanguinem buffonis assumens solet perpeti cardiacam passionem et si non subito iuvatur occupabitur tandem morte. Causa vero huius est cum talis sit animal frigidum ac etiam venenosum et huiusmodi sua disposicione corrumpit et obfuscat spiritus cordiales, quare evenit tremor cum cardiaca passio non sit quasi aliud quam cordis indebita concussio seu tremor. Cum vero est ut promisso vomitu sumat z II pulveris smaragdi cum bono vino. Et breviter curatur sicut tremor cordis. Et si sumentur eius sputum accidentia conforma sequerentur. Et est in hoc utile valde ingredi corpus mule vel alterius animalis. Bezoar vero eius est sumere de pulvere lapidis qui inventur in capite eius secundum Conciliatorem, secundum vero alios ruta. Sumatur granus dictus pulveris cum vino decoctionis rute et res perfectior habeatur.

\section{b) De sanguine hominis rufi et colerici}

Sanguinem hominis rufi et colerici et precipue irati assumentes furiam et alienacionem sunt perpeti consueti. Causa est cum talis sanguis sit calidus levis et furiosus in evaporacione dispositus, tunc evaporando ad capud ac perturbando spiritus animales causat accidentia supradicta. Cura est ut promisso vomitu bibat de aqua frigida, syrupo nenufarino ac violacio [ ?]. Bezoar vero eius est sumere unum trociscum de tyro et cetera.

\section{c) De sanguine leprosi}

Sanguinem leprosi assumentes perpeti solent melancolicam passionem. Causa vero est cum talis sanguis sit venenosus, melancolicus et corruptus precipue ledet sanguinem et spiritum propter eius simboleitatem intus ipsos repertam, tunc enim taliter infectis sanguine et spiritu pacientes dementes efficiuntur et stulti. Et ista clare patent ex superius enarratis. Cura vero est ut, vomitu provocato, sumat de dyamargariton cum vino decoctionis melisse et maiorane. Gaudiis et leticiis curatur. Bezaor est comedere carnes electorum serpentum capite tamen prius proiectis et cauda iuxta usum et cetera.

\section{d) De sanguine menstruo}

Sanguinem menstruum assumentes efficiuntur lunatici et stulti. Causa vero est sicut dicebatur de sanguine leprosi et cum sanguis menstruus moveatur mensatim, similiter fortius affliget omni mense quare tales lunatici vocabuntur. Et ego novi unam mulierem quae duos ex ipsius exhibicione necavit. Dabat enim ipsum ad finem ut maritus eam plus diligeret, nocumenta tamen ipsius sanguinis ipsa ignorabat quare tribuens eis interfecerat 
ignoranter. Cura est ut promisso vomitu sumat z I pulveris margaritarum cum vino claro. Bezoar vero est sumere dictas carnes serpentum.

\section{e) De sanguine thauri}

Sanguinem thauri assumentes hec solent perpeti nocumenta: difficultatem anhelitus, nauseam, stomachique dolorem. Cause vero sunt nam cum sanguis thauri primo quilibet sanguis thauri sit valde viscosus et tenax ac de facili corruptibilibus tunc fumis et vaporibus elevatis ab ipso ad caput et guttur et ipsis in capite congelatis et inde reductis ad pulmonem et eius cannam repleunt ipsos et in eis resident ac sui viscositate coherent quare difficultas anhelitus producitur. Posset etiam aliter contingere. Nam sua gravitate trahit stomachum ad infra et stomachus eciam trahit dyafragma. Unde ipsius dyafragma latera minus distant et per cuius pulmo quodam modo comprimitur veluti si fundus sacculi ad inferius trahetur tunc ipsius latera adinvicem appropinquarent vel forte aliqua ipsius sanguinis particula ventosatur quare stomachus multa ventositate repletus comprimit etiam dyafragma quare fit anhelitus cum labore. Nausea vero evenit propter ipsius sanguinis unctuositatem et dulcedinem. Et sua maligna corrupcione et gravitate causabitur ibi dolor. Et sic pateant cause predictorum. Cura vero est ut sumat de aqua salita bene calida et non tepida nec in nimia quantitate ne vomitus provocetur, cum periculosus sit in hoc casu et introducens suffocationem. Cibi vero laudabiles in hoc sunt ficus immature et lacticinee, primo lac ficuum est optima medicina. Item piper cum aceto fortissimo sumptum est efficax medicamen. Item cinis ligni ficuum cum aceto exhibitum est medicina electa. Nota quod hec remedia valent in quolibet sanguine stomacho congelato et ex quolibet tali eveniunt huiusmodi nocumenta licet aliquantulum minus prava. Bezoar vero eius est lac ficus sumptum cum aceto.

\section{3 - Christoforus de Honestis, Problemata de venenis, vers 1390, British Library,} Harley 3659, f. 51v.-52, Traité 2, anté-pénultième, avant-dernier et dernier chapitre

\section{a) Capitulum de potu sanguinis russi hominis}

Queritur problemata propter quid est quod ex potu sanguinis russi irati hominis colerici devenitur ad furorem et alienationem mentis. Ratio huius est in prom ( $p$ ) tu quam sanguis eius est furiosus, mobilis et vaporabilis, cuius vapor cum commiscetur spiritibus illius bibentis commovet ipsum ad furiam et promiscet rationem. Preservatio vero a nocumentis proficitur cum vomitu aque frigide et comestione mellonis Indi et cucumeris vel aliorum olerum frigidorum et potu syrupi nenufarim dati cum aqua frigida. Bezaard autem huius veneni est trociscum unus de citro et hoc de isto problemate etc.

\section{b) Capitulum de assumptione sanguinis menstrui et leprosi}

Queritur problemata propter quid est quod ex assumptione sanguinis menstrui et leprosi fit lunaticus et obliviosus ac si esset faturatus. Respondeo primo de sanguine leprosi quare est ut plurimum melancolicus evaporabilis generat passionem melancolicam, quare videtur lunaticus et faturatus et ex sua grossicie oppillat vias memorative virtutis. Nunc secundo dicam de preservatione quae completur cum vomitu et asselatione et ex hiis sepe frequentatis. Tertio dico principaliter quod cura nocumenti confirmati completur cum 
hiis quae valent ad multam passionem inter quibus multum valet usus margaritarum non perforatarum et perforatarum et usus aque mellisse et delectari cum iocalibus et rebus amenis; ; e e quae dixi de sanguine leprosi possumus adaptari ad sanguinem menstruum quod licet sit flegmaticus sanguis leprosi, tamen pro sui corruptione satis attinet nempe melancolice et mandat vapores grossos quos ille sanguis facit. Unde inducit predicta accidentia quorum preservatio et cura proficitur ut dictum est. Bezaard autem horum venenorum est caro serpentis a quo abscisum est capud et cauda per unum palmum et hoc de isto problemate.

\section{c) Capitulum de potu sanguinis tauri noviter extincti}

Queritur problemata propter quid est quod ex potu sanguinis recenter extincti accidit difficultas hanelitus et dolor stomaci et vehemens angustia et nausea etc. Respondeo quod causa difficultatis hanelitus est quare talis sanguis congellatur in stomaco. Unde aggravando fundum exprimit diaphraga. Actitur sibi congelatio quare sanguis bovinus est sanguis grossus et viscosus non multe caliditatis et possibile est difficultare hanelitum sine congellatione sanguinis per simplicem agravationem omnis et eadem est causa doloris stomaci et nausee et angustie. Sed cum quereres quantum magis accidit hoc si sanguis sit noviter extractus ex tauro, dico quod difficultas hanelitus contingit ex eo sive noviter sive per tempus extractus fuerit ex tauro quare caliditate actuali est causa nauseationis et ex inde fit dolor stomaci et angustia et ad hoc coadiuvat modus saporis eius calidus. Secundo dico de modo preservationis a nocumento eius, unde admiscendum est in potu eius salitam cum aceto calidam sic tum quum non nauseat, quare vomitus non est provocandus in talibus, timore suffocationis. Similiter conferunt ad hoc ficus immature comeste et semen caulis comestum et piper cum aceto et quecumque valentia ad coagulationem lactis in stomaco. Similiter valet clistere et solutio ventris cum hiis medicinis quas patiens tollerare potest et generaliter valent omnes medicine conferentes in congelatione sanguinis. Et idem quidem modus est curationis iam dicto, eo quo evacuato stomaco desinunt accidentia. Et si aliquis dolor stomaci remanserit aut alterius accidentis confortentur et succurantur cum confortantibus stomacum et aliis notis. Bezoard autem est coagulum leporis et lac fici cum aceto. Et scias quod similia accidentia inducit lac coagulatum in stomaco aut coruptum et sanguis quiscumque alius coagulatus licet non ita malitiosa. Et conveniunt etiam istis modus preservationis et curationis cum modis supradictis salvo quod in istis confert vomitus in assumptione sanguinis tauri non competit vomitus ut in predictis tactum est et hoc de isto secundo tractatu dicta sufficiant etc.

\section{4 -Antonio Guaineri, De venenis, 1422, in Opus praeclarum, éd.de Paris, 1525,f. 244 ou BnF lat. 6981, f. 196}

\section{a) De sanguine humano}

Cui in potu datus fuerit sanguis hominis ruffi extractus tempore rixe vel ire permixtionem intellectus cum furore maximo et in verecundiam incurrens paulatim marasmabitur et tandem consumptus morietur. Et huius bezoar est vinum viperinum vel trociscus unius de tyro. Ex conferentibus est aqua cucumeris vel lac seminum suorum ac syrupus de nenufare. 


\section{b) De sanguine tauri vel bovis antiqui}

Sanguis tauri vel bovis antiqui frusta sanguinis expuere facit congelati et dolorem in branchiis et meri cum rubedine lingue ac prefocacione ac spasmum causans mortem inducunt. Huius bezoar est coagulum leporis cum aceto. Ex conferentibus autem est cinis lignorum ficus cum aceto sumptus aut semen caulis vel piper et etiam sumendum acetum fortissimum calidum per se.

\section{c) De sanguine bufonis}

Sanguis buffonis difficultatem anhelitus, tremorem cordis ac sincopim frequentem causans festinam mortem inducit. Et idem facit eius sputum sed mortem celerius inducit quia est venenum deterius sanguine. Horum bezoar est lapis buffonis quem vulgares caprotinam vocant ut supra dicebatur. Ex conferentibus est $z$ I smeraldi cum vino dare ac ventres calidos animalium quadrupedum intrare sepe ut est bos, asinus, mulus, equus et cetera.

\section{d) De sanguine menstruo}

Qui sanguinem menstruum sumpserit aut leprosi lunaticus, maleficus et obliviosus efficitur. Et horum bezoar est trociscus unus de tyro, aut de serpentibus a quibus cauda et caput per palmum fuerint abscissa manducare, sed elixentur primo et prima abiciatur aqua deinde secondo decoquantur radicem diptami in decoctione ponendo. Ex conferentibus autem est $z$ I margaritarum cum aqua melisse potare in aqua quoque tepida balneari et cum puellis conversari cum quibus interdum coeat.

5 - Sante Ardoini de Pesaro, Liber de venenis, vers 1425, IV, 23 à 26, f. 49 à 50v. de l'édition de Venise, 1492

a) De sanguinis bovis sive tauri precipue recenter extracti quiditate et eius natura et accidentibus assumptionem eius consequentibus et eorum accidentibus causis et assumptionis eius signis et preservatione et cura

Sanguinis quidem bovis sive tauri precipue recenter extracti quiditas nota est. Natura eius sicut cuiuscumque sanguinis iuxta precipue Galienum decimo de simplici medicina capitulo secundo, s. de sanguine, calida est et est substancie grosse cito coagulabilis propter quod redditur nature quodammodo venenose...

[Parmi les effets, impossibilité de déglutition et mort par suffocation et extinction de la chaleur corporelle; la contraction des nerfs peut provoquer aussi de l'épilepsie. Avicenne préconise l'évacuation par clystère car le vomissement est déconseillé; autres soins préconisés par Maïmonide.]

b) De lactis vel sanguinis coagulati seu congelati precipue in pectore vel stomacho vel intestinis vel vesica quiditate et eorum natura et accidentibus assumptionem utriusque eorum consequentibus et eorum accidentium causis et assumptionis eorum signis et preservatione et cura

Sanguinis et lactis coagulati seu congelati precipue in pectore vel in stomaco vel in intestinis vel in vesica nempe quiditas omnibus nota est. Si autem contra hoc 
instetur quare ypocras sexto afforismorum afforismo secundo asserit quod si sanguis in ventrem preter naturam effundatur, necesse est in saniem converti, ergo non coagulatur seu congelatur in prefatis locis ut presupposui. Respondeo iuxta mentem galieni in commento predicti afforismi quod ypocras ibi per saniem non intellexit veram et propriam saniem sed intellexit qualitatem extraneam qua sanguis a sua natura mutatur. Natura vero cuiuscumque sanguinis in sua sinceritate existentis calida est et humida. Natura autem cuiuscumque lactis in sua sinceritate existentis frigida est et humida sicut clare ex auctorum mentibus declaravi in questione mea qua quesivi utrum lac in idropisi a causa frigida competat.

Natura vero sanguinis et lactis coagulati seu congelati et precipue in pectore vel in stomaco vel in intestinis vel in vesica est fere consimilis; consimilem quodammodo propterea curam exigens est namque venenosa precipue cum aliquod eorum notabili tempore in corpore seu in predictarum concavitatum aliquam moram traxit. In quacumque namque earum potest sanguis coagulari et moram trahere, lac vero non nisi in stomaco vel intestinis. Intelligendo de lacte ab extra corpus ad intra ipsum assumpto et non in mulierum mammillis generato. [...] Verum quare presentis propositi est solum principaliter derterminare de natura sanguinis et lactis qud ab extra corpus ad intra ipsum assumitur et postea in ipso coagulatur contrahendo precipue notabili tempore in eo moram quare de sanguine et lacte aliter in corpore seu ipsius partibus coagulatis famosi auctores in propriis capitulis specialem faciunt mentionem ad quod pro eorum notitia et cura debet haberi recursus; idirco conclusive dico quod natura sanguinis et lactis assumpti et postea coagulati precipue in stomaco vel in intestinis postquam presertim in ipsis notabili tempore moram traxit est frigida et venenosa.

Suivent les accidentia: infrigidatio corpori et rigor at aliquando febris et mollificatio et nausea stomaci et tumor ventris et color aliquando croceus et sudor frigidus, parvitas pulsus, prefocatio, strictura anhelitus, sincopis...

Puis les signa et les curae qui portent plutôt sur le lait que sur le sang.

c) De sanguinis menstrui et sanguinis leprosi quiditate et eorum natura et accidentibus assumptionem cuiuslibet eorum consequentibus et eorum accidentium causis et assumptionis cuiuslibet eorum signis et preservatione et cura

Sanguinem menstruum voco non omnem sanguinem ex matrice (e) manantem sed tantummodo sanguinem naturaliter ex matrice mensatim ruentem seu emanantem sive mensatim naturaliter ruere seu emanare ex matrice debentem. Sanguinem vero leprosi assero esse sanguinem ex leproso seu leprosa qualitercumque extractum. Natura cuiuslibet prefati sanguinis est frigida et sicca et melancolica et grossa. Accidentia consequentia assumptionem cuiuslibet predictorum sunt quae assumens videtur esse lunaticus seu facturatus seu maleficiatus et fit obliviosus et leprosus...

[suivent les causes des accidentia et les signa puis les curae]

...Geber in libro de floribus naturarum : si servaveris menstruum mulieris et dederis alicui ad bibendum, fiet leprosus; et si dederis in balneo cito morietur... Retulerunt mihi quidam medicorum quod ipsi invenerunt cum magno scrutinio et sciverunt tam a scriptis quam a suis antecessoribus quod quedam meretrices deceperunt sic plures manifeste. Fuit autem illud in quo fefellerunt eos sanguis menstruus in parva quantitate 
in cibis propinatus et inde passi sunt cruciatos maximus, hoc autem numquam inveni scriptum in libris medicorum quousque ad hunc diem legi et multo minus inveni tractatum seu capitulum speciale de regimine et cura ipsius; retulerunt nihilominus mihi prefati medici quod ipsi et plures in principio ab huiusmodi langoribus cum regimine generali supradicto asserentes quod eorum cura fit si sumant frequentes medicinas per se vel simul mixtas... Horum tamen nullam habeo experientiam, videtur mihi expedire ut reserem ea quibus alii a me possint consequi iuvamentum ut experiatur prudens et probet ea secundum quod sibi videbitur expedire et mihi quidem videtur expedire ut non sumatur cibus de manu suspecti nisi prius ipse comederit ex eo etiam in magna quantitate sicut faciunt coci quorundam regum quos ego vidi.

d) De sanguinis hominis colerici ruffi extracti tempore rixe seu furoris quiditate et eius natura et accidentibus assumptionem cuiuslibet ipsius consequentibus et eorum accidentium causis et assumptionis ipsius eorum signis et preservatione et cura

Sanguinis hominis colerici ruffi tempore rixe seu furoris sui extracti nempe quiditas nota est. Natura eius calida et sicca valde et generativa humoris calidi et sicci valde adeo ut dici possit quodammodo venenosa. Accidentia consequentia assumptionem ipsius sunt furor mentis, permixtio intellectus seu alienatio et inverecundia. Causa predictorum accidentium sunt vapores furiosi excessive calidi et sicci ellevati ad cerebrum se spiritibus precipue animalibus commiscentes... Preservatio fit caute se precavendo ab assumptione eius. Cura vero eius fit cum vomitu celeriter facto post ipsius assumptionem et postea cum rebus valde frigidis et humidi notis a perito medico...

6 - Jean Martin Ferrari de Parme, De vitandis venenis, 1455, Oxford, Bodl. Can. Misc. 127, tractatus 4s de venenis animalium intus assumptorum, ch. 14, 16, 17, 18, f. 43 et $s q$.

\section{a) De bibente sanguinem botracis}

Item si contingeret hominem bibere sanguinem botracis, incureret cardiacam passionem. Et causa est quare ex frigidate dicti sanguinis relati ad hominem mortificatur spiritus cordis. Et intus accidit cardiaca passio et toti corpori infrigidacio. Modus autem preservacionis et curacionis compleri potest eo modo quo dictum fuit in morsu cure botracis. Et ultra hoc compectit medicina ad cardiacam et lapis smaralgdi pulverizatus z I cum uno albo. Item confert intrare corpus animalis magni noviter interfecti et maxime mulli vel equi. Bezoar in hoc secundum Conciliatorem est lapis inventus in capite botracis.

\section{b) De bibente sanguinem hominis colerici}

Item si contingeret homini bibere sanguinem hominis colerici irati, deveniret ad furorem et alienationem intus. Huius ratio est impromptus cum dictus sanguis est furiosus, mobilis et vaporabilis, cuius vapor cum commiscetur spiritibus bibentis eos admovet ad furiam. Et permiscet rationem. Preservatio vero a nocumentis preficitur cum vomitu subito facto cum hiis quae dicta sunt superius. Sed cura postquam nocumenta inducta sunt preficitur cum potu aque frigide et cum comestione cucumeris, curcume [?], 
melonis indi et aliorum olerum frigidorum cum potu syrupi nenufarini cum aqua frigida. Bezoar autem huius veneni est trociscus de tyrro unus.

\section{c) De bibente de sanguine mestruo (sic)}

Item quia contingere potest hominem bibere de sanguine mestruo vel de sanguine hominis leprosi et tunc homo fit lunaticus et obliviosus ac si esset quasi faturatus. Respondeo et dico quod causa istorum accidentium est ista : primo de sanguine leprosi cum sit multum melancolicus, evaporando ad cerebrum, generat passionem melancolicam et sua grossicie opillat vias memorative virtutis. Quare videtur lunaticus et quasi afacturatus. Et quemadmodum de sanguine leprosi dicere possum de sanguine mestruali qui, licet sit flegmaticus magis quam sanguis leprosi, tamen prope sui corupcionem atinet satis nempe melancolie et mandat ad cerebrum vapores grosses, sic ille leprosi, unde inducunt accidentia supradicta. Preservacio nocumenti completur cum vomitu accelerato ex frequentato cum rebus detur in cura generali. Sed cura nocumenti confirmati completur cum hiis que vallet ad melancolicam passionem intus, quia multum vallet usus margaritarum perforatarum. Et usus aque melisse et delectari cum iocalibus et rebus amenis. Bezoar autem horum venenorum est caro serpentis a quo abscissum sit caput et cauda per unum palmum.

\section{d) De bibente sanguinem thauri}

Item si potaretur sanguis thauri extractus recenter, accidit difficultas hanelitus, dolor stomachi vehemens, angustia et nausea. Et causa istorum accidentium est et difficultatis hanelitus quare congellatus tallis sanguis in stomacho unde agravandus fondum comprimitur diafragma. Et eadem est causa angustie et doloris stomachi et nausee. Sed posset aliquis dicere quare magis accidit ista accidentia si sanguis est noviter extractus quam si prae tempus fuisset extractus. Respondeo et dico quod difficultas hanelitus ita contigit uno sicut alio sed alia accidentia contingunt magis ex noviter extracto quia sua actuali caliditate est magis nauseativis ex inde sequitur dolor et angustia stomachi. Et ad hoc coadunat modus saporis eius quem aboret multum natura vestra. Modus preservationis a nocumentis eius est dare in potu aquam salitam cum aceto calidam sic factam quod non nauseat quare vomitus est precavendus in tallibus, timore prefocacionis. Similiter conferunt ad hoc fichus immature comeste et semen caulis comestum et piper cum aceto. Et quecumque vallent ad coagulacionem lactis in stomacho. Similiter vallet clistere et solutio ventris cum hiis medicinis quas paciens tolerare potest. Et generaliter vallent omnes medicine conferentes in congelacione sanguinis sed si quid doloris stomachi remanserit aut alterius accidentis, [manque sans doute un verbe, voir plus haut le passage quasi identique de Honestis] confortantibus stomachum cum medicinis noctis. Bezoar est semen caulis infuxum in aceto. Item coagulum leporis et lac fichus cum acceto est etiam bezoar dicti veneni. Sed est notandum quod quasi similia accidentia inducunt lac coagulatum in stomacho aut corruptum et sanguis quicumque alius congelatus, licet non ita maliciose. Et convenit in hiis modis preservacionis et curacionis cum modis supradictis salvo quod in hiis confert vomitus. In assumpcione vero sanguinis thauri non conpectit, timore prefocacionis. 
Franck Collard - Université de Paris Ouest Nanterre, EA 1587, Département d'histoire, 200 avenue de la République, F-92001 Nanterre cedex

\section{Le poison et le sang dans la culture médiévale}

Élus, somme toute récemment, au rang d'objets d'histoire, le poison et le sang entretiennent des relations complexes dans les représentations médiévales qui, tout à la fois, les opposent en matière juridique et criminelle mais pas toujours, les relient (venenum a vena) en matière médicale et les fusionnent même en matière proprement «vénénologique» comme le montrent les traités des poisons où la toxicité du sang animal et humain fait régulièrement l'objet de développements.

sang - poison - crime - médecine.

\section{Poison and Blood in Medieval Culture}

Recently admitted among historical subjects, poison and blood have complicated relationships in medieval representations which, at once, contrast them in juridical and criminal matter but not always, link them together (venenum a vena) in medical matter and even combine them in toxicological matter as treatises on poisons show it, where toxicity of animal and human blood is regularly treated.

blood - poison - crime - medicine. 
